\title{
Kinetic and morphological investigation of calcium sulfate dihydrate (gypsum) scale formation on heat exchanger surfaces in the presence of inhibitors
}

\author{
Z. Amjad \\ Walsh University, Department of Chemistry, Division of Mathematics and Sciences, \\ 2020 E. Maple Street, North Canton, Ohio 44720 \\ E-mail: zamjad@walsh.edu
}

\begin{abstract}
The kinetics of calcium sulfate dihydrate $\left(\mathrm{CaSO}_{4} \cdot 2 \mathrm{H}_{2} \mathrm{O}\right.$, gypsum) scale formation on heated metal surface from aqueous solution has been studied by a highly reproducible technique. It has been observed that gypsum growth takes place directly on heated metal surface without any bulk or spontaneous precipitation in the supersaturated solution. A variety of maleic acid based polymers with different functional groups have been examined for their inhibitory effect on gypsum growth. The results indicate that amount of gypsum scale formed on heated metal surface is strongly affected by polymer dosage and the functional groups present in the polymer. Scanning electron microscopic investigations of the gypsum crystals grown in the presence of anionic polymeric additives show that structures of these crystals are highly modified. Results on the performance of various surfactants and biocides are presented.
\end{abstract}

Key words: calcium sulfate dihydrate, gypsum, scale, maleic acid polymers, heat exchanger, crystal morphology.

Received: May 12, 2017. Published: June 21, 2017.

doi: $\underline{10.17675 / 2305-6894-2017-6-3-4}$

\section{Introduction}

In recent years, considerable attention has been given to the various forms of calcium sulfate crystallizing from aqueous solution as affected by temperature, $\mathrm{pH}$, solution stoichiometric ratio of lattice ions, and impurity level [1-3]. These and other important factors involved in the nucleation and growth of calcium sulfate dihydrate $\left(\mathrm{CaSO}_{4} \cdot 2 \mathrm{H}_{2} \mathrm{O}\right.$, gypsum), hemihydrate $\left(\mathrm{CaSO}_{4} \cdot 1 / 2 \mathrm{H}_{2} \mathrm{O}\right.$, plaster of Paris), and anhydrite $\left(\mathrm{CaSO}_{4}\right)$ should have direct application to the control and inhibition of scale formation. To preclude an excessive rise of operating costs, scale formation has to be prevented. In order to reduce or mitigate scaling, various approaches have been suggested, the most common being the use of small amount (few milligram per liter, $\mathrm{mg} / \mathrm{L}$ ) of scale control additives. The main requirements for an effective additive include: (a) readily available, (b) effective at low dosages, (c) cost effective, (d) non-toxic to environment, (e) stable under oxidizing conditions, (f) resists degradation at high temperatures, and $(\mathrm{g})$ compatible with water treatment formulation components. 
The effectiveness of a number of inhibitors in preventing or reducing the crystallization of gypsum has been investigated. Amjad [4] in a study using the seeded growth method, reported that trace amounts of low molecular weight poly(acrylic acid), PAA, can stabilize supersaturated solutions and lengthen the induction time before the onset of crystallization. The duration of induction times observed in the presence of polymers was found to be greatly influenced by the polymer concentration, solution temperature, $\mathrm{pH}$, and the amount of gypsum seed crystals added. Smith and Huilin [5] have examined the effect of number of polyelectrolytes on the growth rate of gypsum. Polymers containing carboxyl groups, such as PAA, and formulated products containing PAA were shown to be particularly effective as gypsum growth inhibitors. Amjad [6] in studies on the evaluation of polymers as gypsum scale inhibitors, showed that polymer composition, molecular weight, and ionic charge of the polymer play important roles in imparting the inhibitory activity to the polymer. Among the various homopolymers evaluated, PAA showed the best performance whereas neutral and cationic charged polymers were the least effective inhibitors.

Recently, the performance of carboxymethyl inulin (CMI) with different degree of carboxylation as inhibitors for various scaling systems (e.g., $\left.\mathrm{CaC}_{2} \mathrm{O}_{4} \cdot \mathrm{H}_{2} \mathrm{O}, \mathrm{CaCO}_{3}, \mathrm{BaSO}_{4}\right)$ and iron oxide dispersants has been investigated [7,8]. Results of these studies reveal that CMI exhibits good inhibitory and dispersancy activities and its performance strongly depends on the degree of carboxylation. In another study, Zeiher [9] reported that maleic acid-based hybrid polymers also show good inhibitory activity for various scaling systems. Dogan et al. [10] using the spontaneous precipitation method, investigated the influence of poly(ethylene oxide)-block-poly(methacrylic acid) polymers as gypsum growth inhibitors. Results of their study show that inhibition increases with acid content of the polymer. The influence of various additives (i.e., synthetic, bio-, hybrid polymers) for their effectiveness as gypsum scale inhibitors on heated metal surfaces has been recently reported. It was shown that in general synthetic polycarboxylates perform better than natural, bio-, and hybrid polymers [11,12]. Moreover, it was reported that copolymers such as acrylic acid:hydroxypropyl acrylate and acrylic acid:2-acrylamido-2-methyl propane sulfonic acid exhibit poor performance compared to low MW PAA $[6,12,13]$.

In our earlier studies using spontaneous precipitation conditions we investigated the effect of various acrylic acid and maleic based homo- and copolymers as gypsum scale inhibitors. It was shown that performance of polymers is markedly affected by various cationic charged impurities $[14,15]$. To understand the impact of monomers containing different functional groups with scale forming salts, we examined the inhibitory activity of maleic acid based copolymers of varying molecular weight as gypsum scale inhibitors on heated metal surfaces. This study also presents results on the impact of various anionic, non-ionic, and cationic surfactants, and cationic biocides on the performance of gypsum scale inhibitors. In addition, scanning electron microscopy and $\mathrm{x}$-ray diffraction techniques were used to study the morphology of gypsum crystals grown on the heated metal surfaces in the absence and presence of inhibitors. 


\section{Experimental}

\subsection{Materials}

Grade A glassware, reagent grade chemicals, and double-deionized distilled water were used. Calcium chloride solutions were standardized by ethylenediamine tetraacetic acid titration method. Sodium sulfate solutions were standardized by ion exchange method. The polymers tested were selected were commercial and experimental materials and their solutions were prepared on dry weight basis. Table 1 lists the polymers tested.

Table 1. Polymers evaluated.

\begin{tabular}{|c|c|c|c|}
\hline Polymer & Ionic charge & MW & Acronym \\
\hline Poly(maleic acid) & negative & $0.65 \mathrm{k}$ & MA \\
\hline Poly(itaconic acid) & negative & $10 \mathrm{k}$ & IA \\
\hline Poly(vinyl pyrrolidone) & neutral & $18 \mathrm{k}$ & VP \\
\hline Poly(acrylic acid) & negative & $2.3 \mathrm{k}$ & AA \\
\hline Poly(maleic acid:vinyl pyrrolidone) & $\begin{array}{c}\text { negative } \\
\text { neutral }\end{array}$ & $15 \mathrm{k}$ & MVP1 \\
\hline Poly(maleic acid:vinyl pyrrolidone) & $\begin{array}{c}\text { negative } \\
\text { neutral }\end{array}$ & $60 \mathrm{k}$ & MVP2 \\
\hline Poly(maleic acid: vinylpyrrolidone: vinyl acetate) & $\begin{array}{c}\text { negative } \\
\text { neutral }\end{array}$ & $15 \mathrm{k}$ & MVPA \\
\hline Poly(maleic acid:vinyl alcohol) & $\begin{array}{c}\text { negative } \\
\text { neutral }\end{array}$ & $<15 \mathrm{k}$ & MVOH \\
\hline Poly(maleic acid:acrylic acid) & negative & $<20 \mathrm{k}$ & MAAA \\
\hline Poly(maleic acid:itaconic acid) & negative & $<5 \mathrm{k}$ & MIA \\
\hline Poly(maleic acid:sulfonated styrene) & negative & $<5 \mathrm{k}$ & MSS \\
\hline
\end{tabular}

Scaling index $(\mathrm{SI})=\log \mathrm{IAP} / K_{\mathrm{sp}} 1.78$ and 2.09 for calcium sulfate anhydrite and calcium sulfate dihydrate

\subsection{Gypsum Deposition Protocol}

Supersaturated solutions of calcium sulfate were prepared in a double-walled, water jacketed crystallization cell of about $980 \mathrm{~mL}$ capacity. The calcium sulfate solution has the following characteristics: $1,380 \mathrm{mg} / \mathrm{L} \mathrm{Ca}$ (as $\mathrm{Ca}^{2+}$ ), 3,315 mg/L SO $4\left(\right.$ as $\left.^{2-} \mathrm{SO}_{4}^{2-}\right), 2,450 \mathrm{mg} / \mathrm{L}$ $\mathrm{Cl}\left(\right.$ as $\left.\mathrm{Cl}^{-1}\right), 1,587 \mathrm{mg} / \mathrm{L} \mathrm{Na}\left(\right.$ as $\left.\mathrm{Na}^{+}\right), \mathrm{pH} 5.60$. The heat exchanger tubes $(40 \mathrm{~cm}$ long, 1.0 $\mathrm{cm}$ outer diameter) were used. These tubes (Admiralty brass (AB), stainless steel 304, SS) were suspended from the lid of the crystallization cell and immersed in the supersaturated solution. The total metal surface area in contact with the calcium sulfate solution was typically about $81 \mathrm{~cm}^{2}$. The tubes were chemically cleaned and rinsed thoroughly with 
distilled water to avoid any surface imperfections and impurities. Scale deposition experiments were initiated by immersing the metal tube in the calcium sulfate supersaturated solutions. A temperature differential was provided by circulating hot water, maintained at $67 \pm 0.5^{\circ} \mathrm{C}$, through the tube, and cold water, $6 \pm 0.4^{\circ} \mathrm{C}$, through the outside of the crystallization cell. The test rig used is shown in Figure 1. Within $\sim 5$ minutes, a steadystate temperature was reached and the bulk solution temperature remained at a constant value. To minimize corrosion of the brass heat exchanger during scale deposition, tolyltriazole corrosion inhibitor was used. During the scale deposition experiment solution samples were withdrawn from time to time and filtered through $0.22 \mu \mathrm{m}$ filter paper, and soluble calcium was analyzed by EDTA titration. In addition, during the experiment solution temperature was also monitored as a function of time.

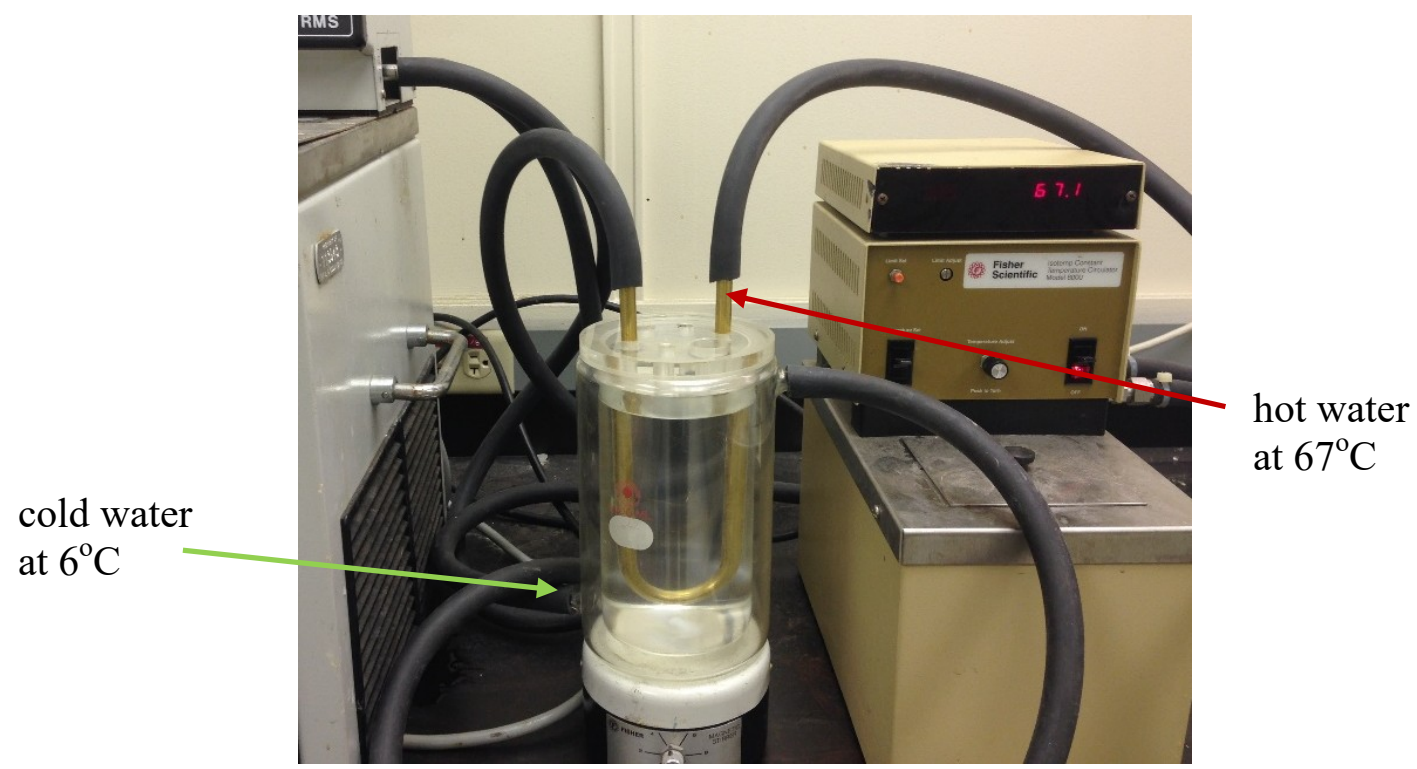

Figure 1. Gypsum deposition test rig.

\section{Results and Discussion}

Concentrations of the ionic species in the calcium sulfate supersaturated solutions at instant during the gypsum growth experiments were calculated from the measured calcium ion concentrations using the successive approximation methods described previously [13]. Allowance was made for the presence of the ion pair, $\mathrm{CaSO}_{4}$, and calcium-inhibitor complexes. The scaling index, defined as the ratio of the ion activity product over the thermodynamic solubility product was calculated for each of the potentially forming solid phases, and the calculated values are shown in Table 1. As indicated the solutions are supersaturated with respect to calcium sulfate dihydrate and calcium sulfate anhydrite.

Following the immersion of the heat exchanger tube in the metastable solution, the kinetics of gypsum scale formation was followed by withdrawing solution samples at known time and analyzing the filtrate samples for $\mathrm{Ca}^{2+}$ ions. Figure 2 presents the concentration of $\mathrm{Ca}^{2+}$ as a function of time for duplicate experiments carried out in the 
absence of an inhibitor. It is evident that gypsum deposition on heated brass surface begins after an initial induction time, $\beta$, during which there is negligible change in the bulk calcium concentration. The time at which a decrease in calcium concentration was first detected was taken as $\beta$. It can be seen in Figure 2 that, following an induction period ( $24 \mathrm{~min}$ ), gypsum scale formation takes place on the heated brass surface. The reproducibility of the scale formation experiments is shown by the excellent agreement between the results of duplicate experiments. To verify that spontaneous precipitation did not occur during the scale deposition experiment, unfiltered samples were also analyzed for calcium ion and found to be within $\pm 0.5 \%$ of the filtered sample. It is worth noting that as the calcium concentration decreases with time reflecting increased gypsum formation, the solution temperature also decreases with time. The observed decrease in solution temperature confirms insulating characteristics of gypsum scale on the heat exchanger. It has been well documented that thickness and type of scale formed on heat exchanger surface exhibits marked economical effect on the performance of industrial water system $[16,17]$. For example, $1 \mathrm{~mm}$ thickness of gypsum reduces heat transfer efficiency by $\sim 20 \%$ compared to $\sim 50 \%$ observed for biofilm, thus costing billions of dollars in extra fuel and/or electric expenses.

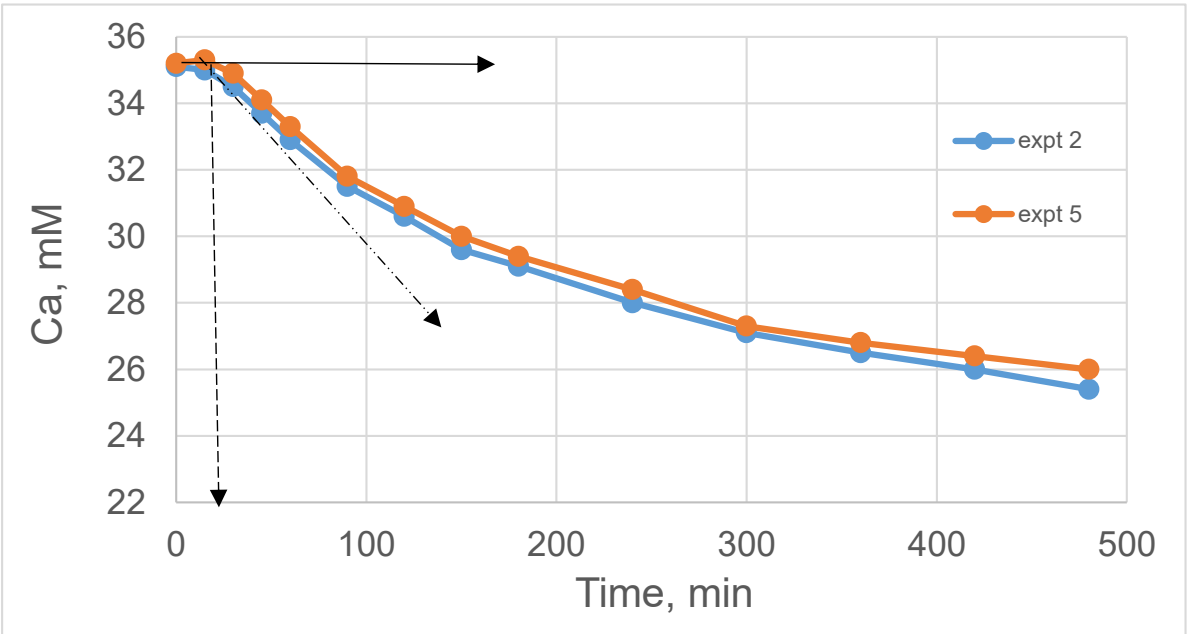

Figure 2. Plots of calcium concentration as a function of time.

\subsection{Kinetics of Gypsum Growth}

The crystallization of gypsum from aqueous solutions containing equivalent concentrations of lattice ions has been shown [13] to follow the rate law of the form:

$$
\text { Rate }=-\mathrm{d} C / \mathrm{d} t=k s\left(C-C_{\mathrm{e}}\right)^{2}
$$

in which $C$ is the total molar calcium ion (or total sulfate) concentrations at time $t, C_{\mathrm{e}}$ is the equilibrium solubility value, and $t$ is the time in minutes, and $k$ is the rate constant and ' $s$ ' is a function of active growth sites on the substrates. Figure 3 presents calcium ion concentration $v s$. time profiles for experiments carried out with two different heat exchanger surfaces namely, brass and stainless steel. Typical plots of the integrated form of 
Eq. (1) are shown in Figure 4 and $k s$ values calculated for experiments using_brass and stainless steel heat exchanger tubes are 0.235 and $0.185 \mathrm{M}^{-1} \mathrm{~min}^{-1}$, respectively. It is worth noting that Eq. (1) satisfactorily represents the rate data even under conditions of metal surface induced nucleation of gypsum.

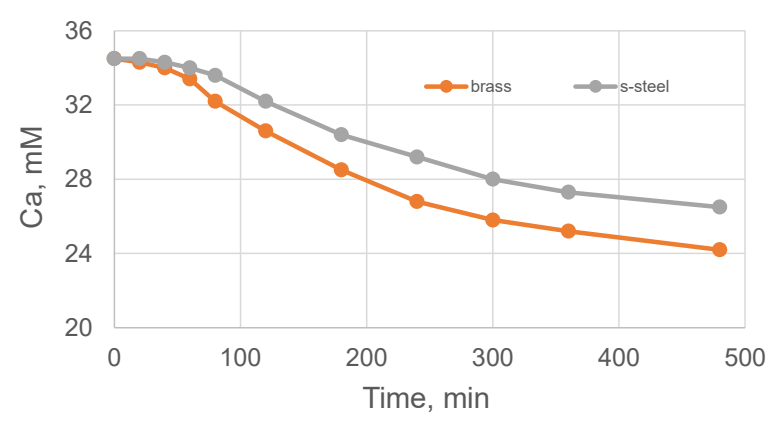

Figure 3. Plots of Ca concentration vs. time for gypsum growth experiments on brass and stainless steel heat exchanger surfaces.

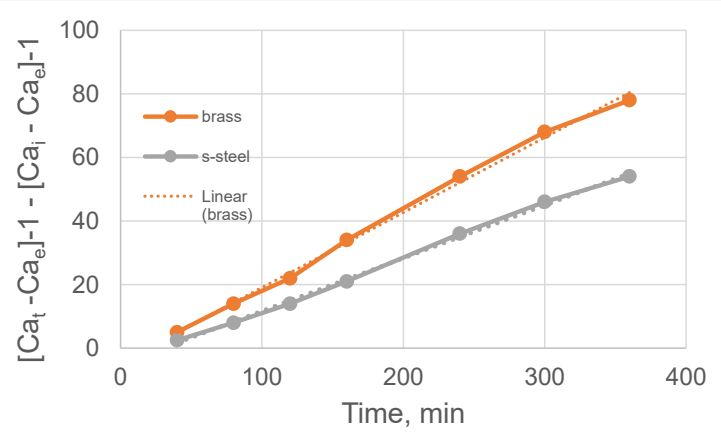

Figure 4. Kinetic plots of Eq. (1) for gypsum growth on brass and stainless steel heat exchanger surfaces.

It has been reported that gas-solid-liquid interfaces play an important role on the nucleation and subsequent attachment of scale crystals on heat exchanger surfaces [18]. Klima and Nancollas [19] in their study proposed that gypsum crystals formed preferentially at the perimeters of gas bubbles. In the present investigation the nucleation and subsequent growth of gypsum crystals were examined visually and by scanning electron microscopy. Figure 5 (A, B, C, D) present photographs of gypsum growth on AB tube at $0,0.25,1.0$, and $2.5 \mathrm{hr}$, respectively. It can be seen that within $0.25 \mathrm{hr}$ of tube immersion in the calcium supersaturated solution, air bubbles start forming on the $\mathrm{AB}$ tube. The gypsum crystals growth at $1 \mathrm{hr}$ and $2.5 \mathrm{hr}$ are presented in Figure $5 \mathrm{C}$ and $\mathrm{D}$, respectively. Figure 5E clearly shows that at $20 \mathrm{hr}$ heat exchanger tube is completely covered with gypsum crystals. 


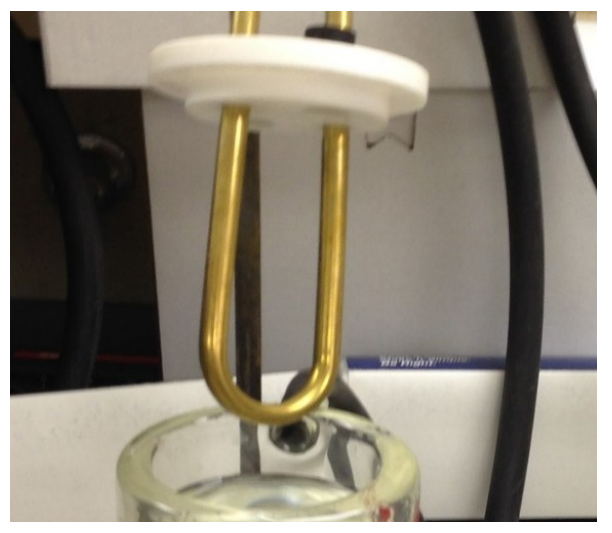

(A) $0 \mathrm{hr}$

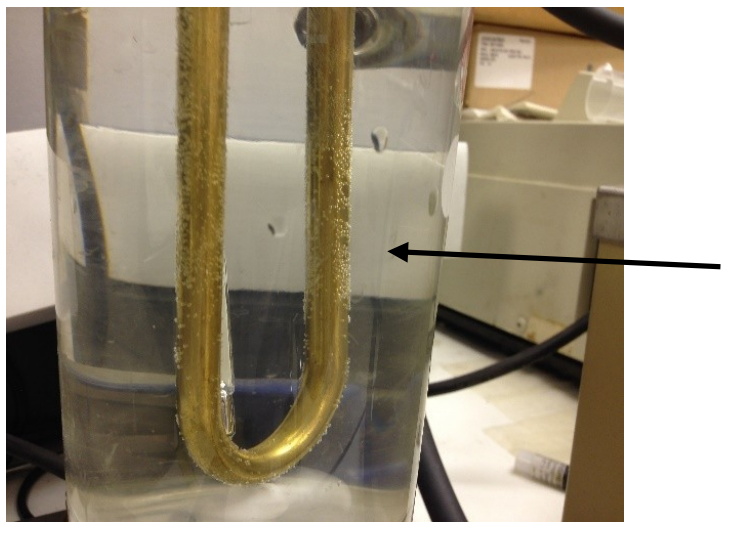

(B) $0.25 \mathrm{hr}$

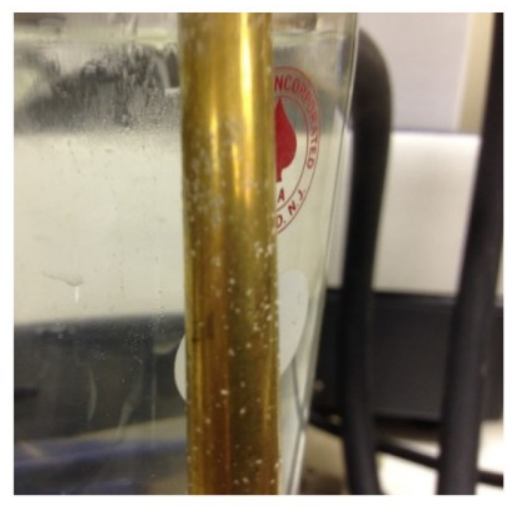

(C) $1.0 \mathrm{hr}$

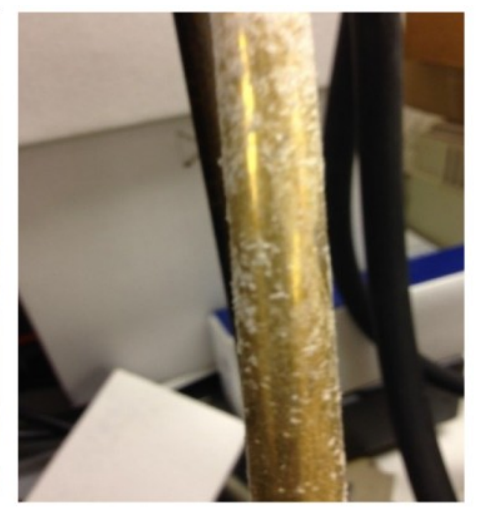

(D) $2.5 \mathrm{hr} \min$

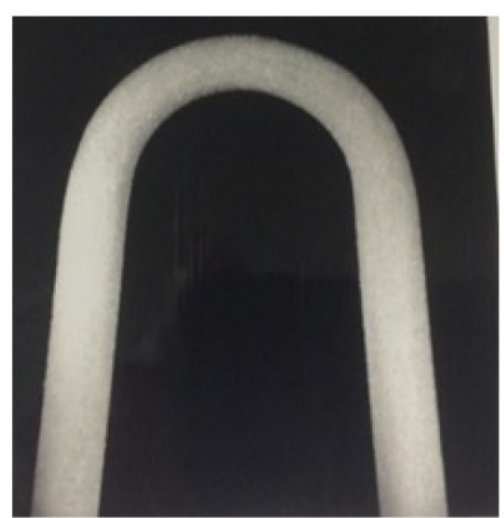

(E) $20 \mathrm{hr}$

Air bubbles formation

Figure 5. Photographs of $A B$ heat exchanger with gypsum deposit as a function of time.

\subsection{Maleic Acid Based Polymers Performance}

Using the experimental protocol described above, a series of gypsum deposition experiments on brass heat exchanger surfaces were carried out in the presence of homoand copolymers. Table 1 presents structures, MW, and acronyms of polymers tested. As illustrated these polymers vary significantly both in terms of ionic charge of the functional groups present in monomer(s) and the MW.

It has been previously reported [4] that influence of polymeric and non-polymeric additives as gypsum growth inhibitors falls into two categories: those additives that affect the induction period and those that show no significant effect on the induction period preceding the gypsum crystal growth. The calcium-time profiles for the first type were observed for the better additive while profiles for the second type were obtained for less effective additives. In both cases the decrease in calcium ion concentration from solutions with increasing reaction time was found to follow the second order rate law [6]. To accommodate both types of behavior, in the present study we have selected, for polymer performance, the amount of calcium remaining in solution at $8 \mathrm{hr}$. When expressed as a function of the total calcium ion present at the beginning of the scale formation experiment, the difference between initial and $8 \mathrm{hr}$ residual calcium ion concentrations 
becomes a measure of the amount of the gypsum scale deposited on the heated metal surface. The choice of $8 \mathrm{hr}$ is arbitrary and, although the selection of different growth time would lead to a change of absolute mass of gypsum scale deposited, it would not affect the relative ranking of polymer effectiveness. For example, in our earlier investigation it was shown that based on $4 \mathrm{hr}$ gypsum growth data, PAA performs better than poly(acrylamide) and copolymer of acrylic: acrylamide [13].

\subsubsection{Homopolymers}

In Figure 7, the amount of gypsum (g) deposited in $8 \mathrm{hr}$ on the brass metal tube is plotted as a function of MA dosage. As can be seen, the amount of gypsum deposited strongly depends on MA dosage. For example, mass of gypsum deposited in the presence of 0.075 and $0.20 \mathrm{mg} / \mathrm{L}$ are 1.25 and $0.71 \mathrm{~g}$, respectively compared to $1.61 \mathrm{~g}$ obtained in the presence of $0.0 \mathrm{mg} / \mathrm{L}$ of MA dosage. As illustrated in Figure 7, increasing the MA dosage by a factor of 5 (i.e., from 0.20 to $1.0 \mathrm{mg} / \mathrm{L}$ ) results in $\sim 9$ fold decrease in gypsum growth.

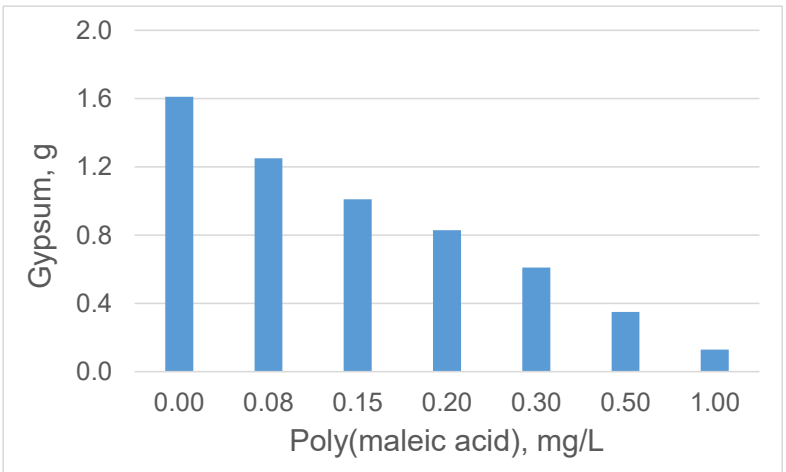

Figure 7. Mass of gypsum grown on brass heat exchanger as a function poly(maleic acid) concentration.

It is worth noting that similar gypsum growth $v s$. dosage profile as observed in the present study was also seen for PAA [13].

Figure 8 presents mass of gypsum deposited on brass heat exchanger in $8 \mathrm{hr}$ in the presence of $0.5 \mathrm{mg} / \mathrm{L}$ of homopolymers, i.e., poly(maleic acid), MA; poly(acrylic acid), AA; poly(itaconic acid), IA and poly(vinyl pyrrolidone), VP. The data suggest that all polymers containing carboxylic acid $(-\mathrm{COOH})$ group show good to excellent performance as gypsum scale inhibitors. As illustrated in Figure 8 under similar experimental conditions, the mass of gypsum scale formed in the presence of polymer that is devoid of $-\mathrm{COOH}$ group such as VP is $1.54 \mathrm{~g}$ compared to $1.61 \mathrm{~g}$ obtained in the absence of polymer. These results clearly show that polymer containing non-ionic charge functional group is an ineffective gypsum growth inhibitor. It should be noted that the results obtained in the present investigation are consistent with previous published work on the performance of homopolymers of acrylamide and 2-ethyloxazoline (containing non-ionic (neutral charge) functional groups) $[13,20]$. It is worth noting that whereas homopolymer of 2-ethyloxazline exhibits poor performance as gypsum inhibitor, this polymer has been 
reported to show excellent performance for silica polymerization [21]. Thus, it is clear that performance of polymers strongly depends on the scaling system being inhibited. Based on the data presented the homopolymers can be ranked, in terms of decreasing effectiveness, as follows: $\mathrm{AA}>\mathrm{MA} \geq \mathrm{IA}>\mathrm{VP} \approx$ no polymer (control).

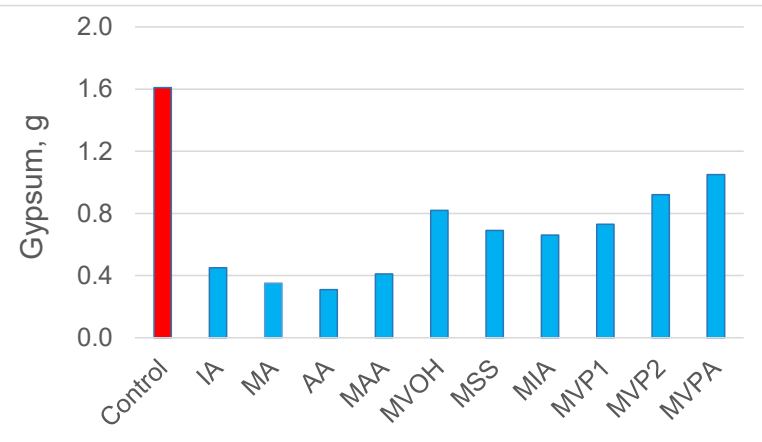

Figure 8. Mass of gypsum grown on brass heat exchanger in the presence of $0.5 \mathrm{mg} / \mathrm{L}$ of various maleic and acrylic acid based homo- and copolymers.

\subsubsection{Copolymers}

In view of the above results suggesting that polymers containing $-\mathrm{COOH}$ group inhibit scale formation, additional experiments were carried out with copolymers containing different functional groups (i.e., alcohol, $\mathrm{OH}$; sulfonic acid, $-\mathrm{SO}_{3} \mathrm{H}$; ester, $-\mathrm{COOR}, N$ pyrrolidone, $-\mathrm{CON}-\mathrm{R}_{1} \mathrm{R}_{2}$ ). Figure 8 presents gypsum deposition data on several copolymers. As can be seen that all polymers tested show decreased performance compared to $\mathrm{MA}$, suggesting that partly replacing $-\mathrm{COOH}$ group with non-ionic or anionic groups i.e., vinyl pyrrolidone, $-\mathrm{SO}_{3} \mathrm{H}$ results in a decreased performance of copolymer. For example, mass of gypsum scale formed in the presence of $0.5 \mathrm{mg} / \mathrm{L}$ of MSS and MOH are 0.69 and $0.72 \mathrm{~g}$ respectively, compared to $0.38 \mathrm{~g}$ obtained for MA. It is worth pointing out that although these copolymers show good to mediocre performance as gypsum inhibitors, MSS has been reported to exhibit excellent performance as calcium phosphate and calcium phosphonate inhibitors and iron oxide dispersants [22]. Thus, it is clear that copolymer performance as scale inhibitor depends on the scale being inhibited. Figure 8 also presents gypsum growth data on two polymers with varying MW. As illustrated, low MW MVP1 performs better than high MW MVP2. For example, mass of gypsum obtained for MVP (MW 6k) is $0.73 \mathrm{~g}$ compared to $0.92 \mathrm{~g}$ obtained for MVP2 (MW $60 \mathrm{k}$ ). The poor performance shown by MVP2 versus MVP1 may be attributed to poor adsorption of high MW MVP on gypsum crystallites due to high degree of coiling and/or steric hindrance. It is interesting to note that similar MW dependence was observed for PAA [13].

The effectiveness of homo- and copolymers of acrylic acid as gypsum scale inhibitors on heated $A B$ surface has been previously reported $[11,13]$. Results of these studies reveal that compared to PAA, copolymers of acrylic acid:hydroxypropyl acrylate (HPA) and acrylic acid:2-acrylamido-2-methylpropane sulfonic acid (SA) exhibit poor performance 
thus suggesting that incorporating of monomers that are devoid of $-\mathrm{COOH}$ groups (i.e., HPA, SA) results in decreased copolymer performance.

\subsection{Effect of surfactants and biocides on polymers performance}

The presence of soluble impurities i.e., trivalent metal ions, biocides, surfactants, etc., and insoluble impurities or suspended solids such as corrosion products precipitated salts, clay, etc., on the performance scale inhibitors has attracted the attention of several researchers. Results of these studies suggest that cationic charged impurities exhibit negative impact on the performance of polymers as scale inhibitors for various scaling salts such as calcium carbonate, calcium phosphate, and calcium sulfate dihydrate presumably due to strong interactions of anionic-cationic species as well adsorption of scale inhibitors on the suspended materials, thus affecting the concentration of scale inhibitors in solution [23, 24, 25].

Surfactants are used in a variety of applications including agrochemicals, laundry detergents, pharmaceuticals, petroleum, mineral ores, personal care, paints, coatings, fuel additives, and photographic films. Surfactants are generally classified into four groups: (a) anionic, (b) non-ionic, (c) amphoteric, and (d) cationic. Cationic surfactants are generally used in textile as a fabric softener. Surfactants are also used in reverse osmosis membrane cleaning formulations [26]. In cooling water systems surfactants are frequently used to emulsify oils, to enhance the penetration of biocides, and to disperse biological mass [27].

In our previous investigations, we reported the influence of surfactants on the performance of polymers as calcium phosphate and calcium sulfate dihydrate inhibitors and as iron oxide dispersants [28, 29, 30]. It was shown that compared to anionic, nonionic, and amphoteric surfactants, cationic surfactants exhibit negative impact on inhibitors performance. Table 2 lists the surfactants tested in the present study. Figure 9 presents the data collected in the presence of $0.5 \mathrm{mg} / \mathrm{L}$ of MA and $10 \mathrm{mg} / \mathrm{L}$ of surfactants and biocides. As illustrated, all surfactants and biocides at $10 \mathrm{mg} / \mathrm{L}$ show no significant impact on the performance of MA. Figure 10 also presents gypsum growth data collected in the presence of MA/surfactant (0.5/10) and MA/biocide blends (0.5/10). As illustrated, only cationic surfactant and cationic biocides at higher concentration $(10 \mathrm{mg} / \mathrm{L})$ shows $\sim 10 \%$ decrease or antagonistic influence on the performance of MA polymer, presumably due to the formation of MA-cationic surfactant/biocide salt.

Table 2. Surfactants and biocides tested.

\begin{tabular}{cccc}
\hline Additive & Ionic Charge & MW & Acronym \\
\hline Sodium xylene sulfonate & Negative & 208 & SXS \\
Octyl phenolethoxylate & Neutral & 624 & OPE \\
Cetyltrimethyl ammonium chloride & Positive & 320 & CTA \\
$n$-Alkyldimethyl benzyl ammonium chloride & Positive & 351 & ABA \\
Tetrakishydroxymethyl phosphonium sulfate & Positive & 406 & TKP \\
\hline
\end{tabular}




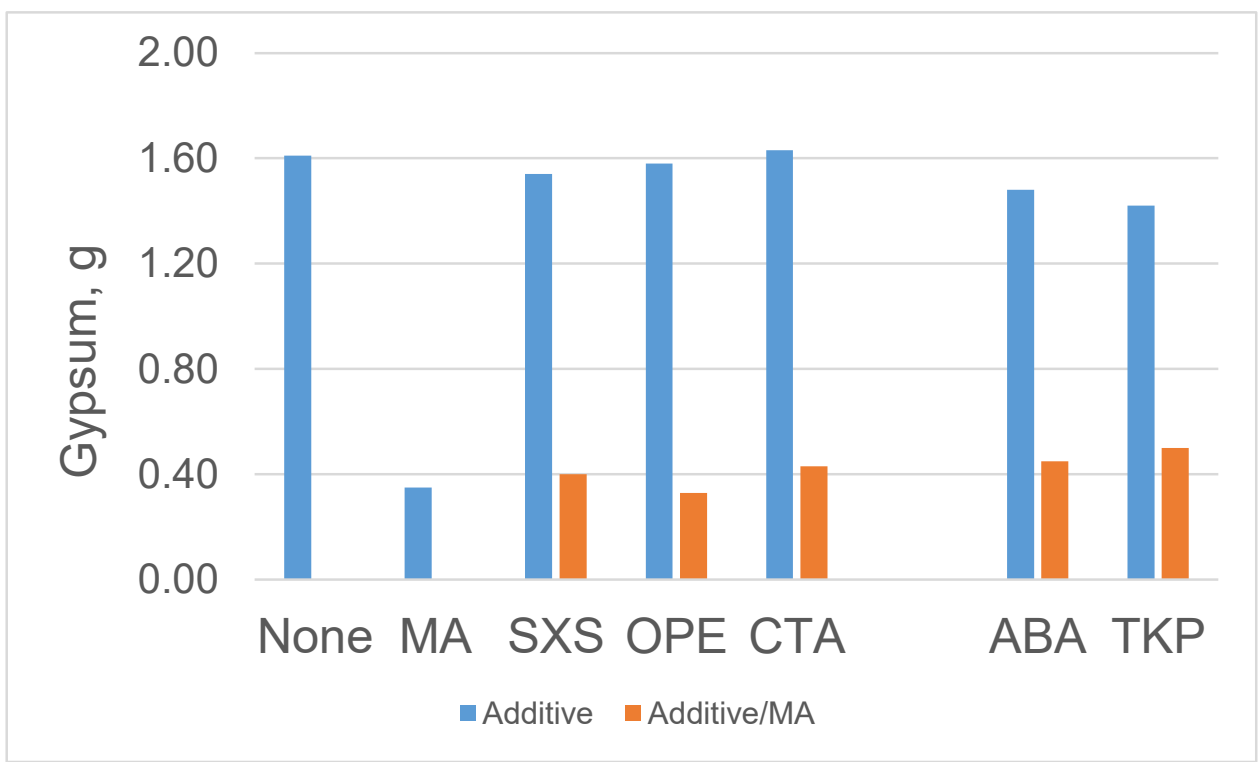

Figure 9. Gypsum growth in the presence of $0.5 \mathrm{mg} / \mathrm{L} \mathrm{MA}, 10 \mathrm{mg} / \mathrm{L}$ additives, and MA/Additive blends.

\section{Characterization of Gypsum Crystals}

It has been reported that the presence of trace amounts of scale inhibitor influences not only the growth rate but also the morphology of scale forming minerals. In some cases, such as calcium carbonate [31] and calcium oxalate [32] the presence of inhibitors also affects the nature of the phase that forms. Photographs were also taken by scanning electron microscopy (SEM) for the subsequent visual analysis in order to access the effects of polymers on crystal morphology. Figure 10 (A, B, C) presents micrographs of gypsum crystals grown in the absence polymer from which it can be seen that nucleation of crystals (Figure $10 \mathrm{~A}, 0.5 \mathrm{hr}$ ) took place at the perimeter of gas bubbles. Figure $10(\mathrm{~B}, \mathrm{C})$ show subsequent growth of gypsum crystals. Moreover, Figure $7 \mathrm{C}$ indicates that in the absence of polymer, gypsum crystals formed are needle type crystals. Figure $10 \mathrm{D}$ presents gypsum crystal grown in the presence of $0.5 \mathrm{mg} / \mathrm{L}$ MVP1. It can be seen that gypsum crystals are highly modified in the presence of copolymer.

The XRD spectra of gypsum deposited on the AB surface from the calcium sulfate supersaturated solution in the presence and absence of MVP1 copolymer are presented in Figure $11 \mathrm{~A}$ and $11 \mathrm{~B}$, respectively. For gypsum deposit in the absence of polymer (Figure $11 \mathrm{~A}$ ), the structure is confirmed to be $\mathrm{CaSO}_{4} \cdot 2 \mathrm{H}_{2} \mathrm{O}$. The ' $\mathrm{d}$ ' and ' $\theta$ ' values are in conformity with the reported values. In both cases with the polymer addition the crystal structure has not been altered (Figure $11 \mathrm{~B}$ ), only the morphology is changed and this is confirmed by the variation in the intensity values and no change in the ' $d$ ' and ' $\theta$ ' values compared to that of control. 


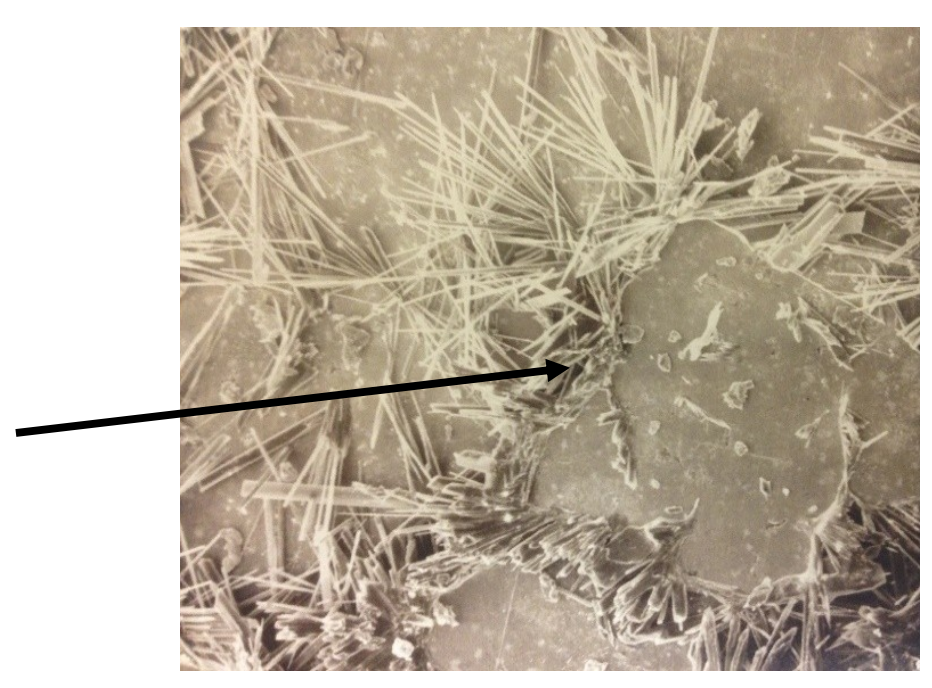

A $(0.5 \mathrm{hr}$, no polymer $)$

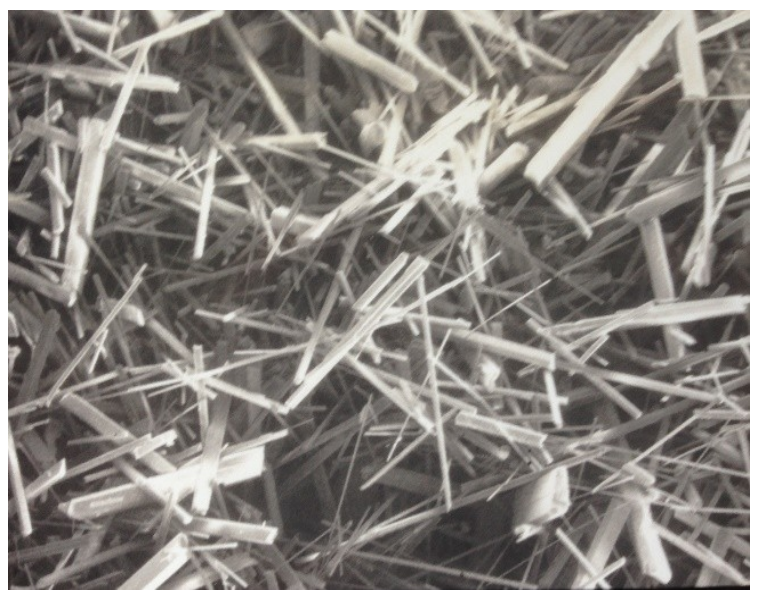

$\mathrm{C}(8 \mathrm{hr}$, no polymer)

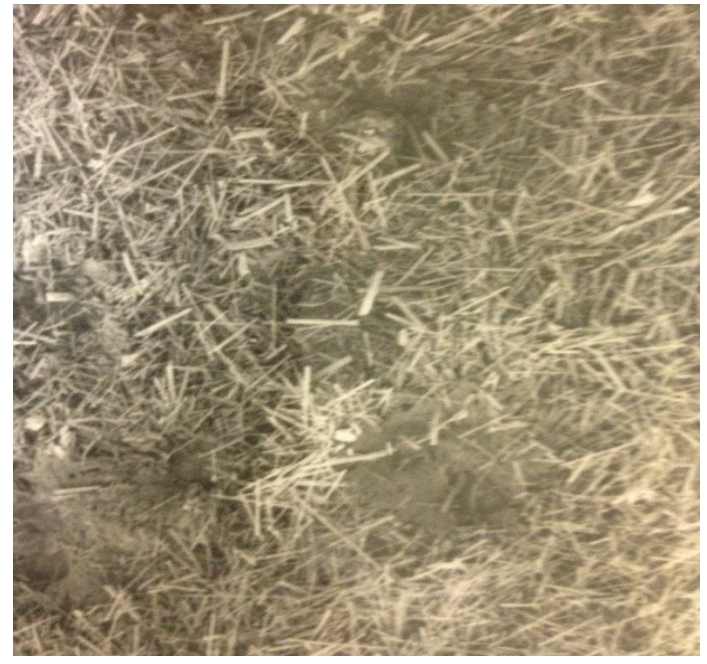

$\mathrm{B}(2.5 \mathrm{hr}$, no polymer)

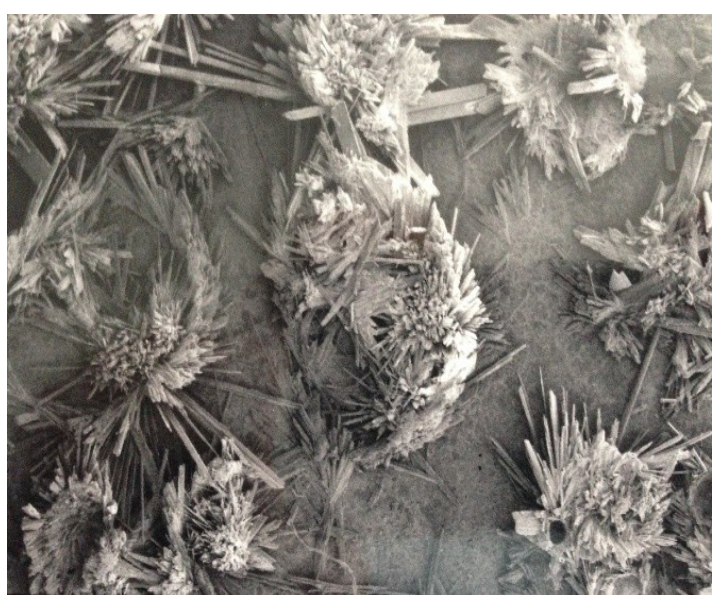

$\mathrm{D}(8 \mathrm{hr}, 0.5 \mathrm{mg} / \mathrm{L} \mathrm{MVP})$

Figure 10. Gypsum growth on brass heat exchanger surface in the absence and presence of polymer and as function of time.

\section{Summary}

The deposition of gypsum crystals on heated metal surfaces has been investigated. Results show that gypsum crystals growth takes place directly on the heated metal surface without any bulk precipitation. Kinetic data also support the application of second order rate law in the crystallization of gypsum from aqueous solution. Gypsum deposition results indicate that performance of polymers as inhibitors depends on both the polymer architecture and polymer concentration. In general, carboxyl acid $(-\mathrm{COOH})$ containing homopolymers i.e., poly(maleic acid), poly(acrylic acid), poly(itaconic acid), exhibit better performance compared to the polymer containing non-ionic group such as poly(vinyl pyrolidone). Gypsum deposition data also reveal that incorporation of monomers containing both bulkier and hydrophobic groups results in decreased performance of the copolymers. 
Under the conditions investigated non-ionic and anionic surfactants up to $10 \mathrm{mg} / \mathrm{L}$ are ineffective in inhibiting gypsum growth. On the other hand, cationic surfactant and cationic biocide show marginal antagonistic effect on maleic acid polymer performance.

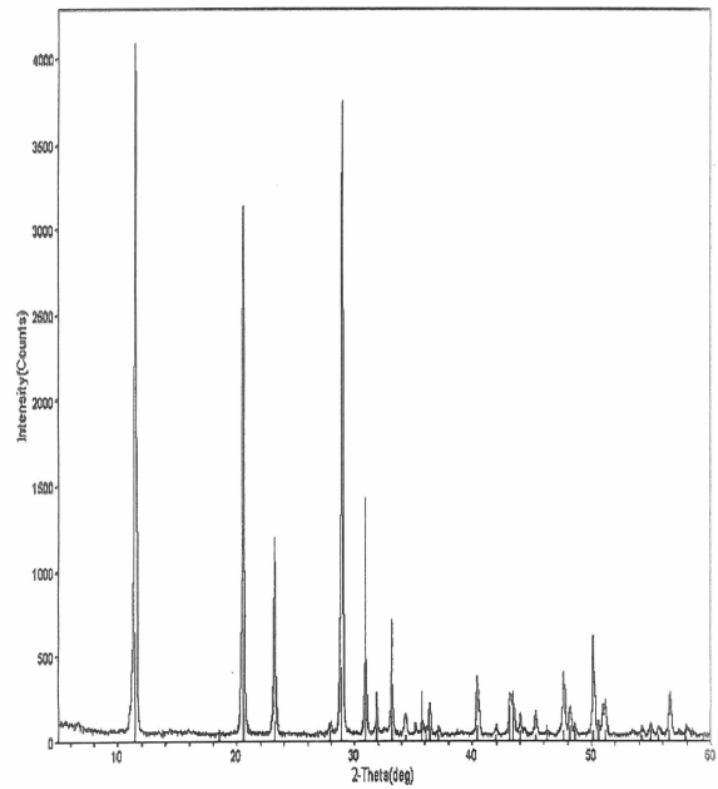

(A)

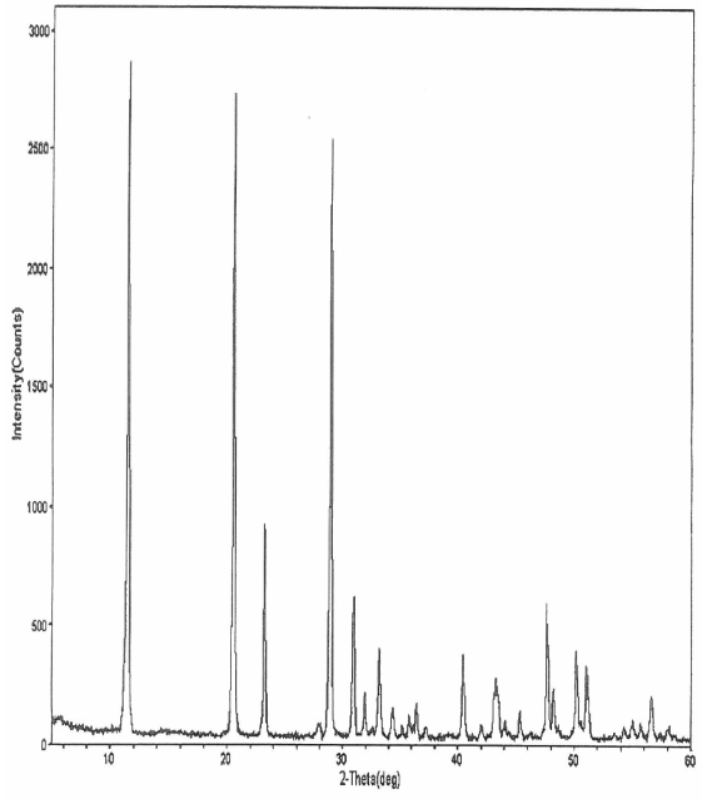

(B)

Figure 11. X-ray diffractograms of gypsum grown in the absence (A) and in the presence of MVP1 copolymer.

\section{Acknowledgements}

The author thanks Walsh University for support to carry out the research and present findings at the NACE International annual convention.

This paper is based on CORROSION 2017 paper no. 9013, presented in New Orleans.

\section{References}

1. N.S. Yehia, M.M. Ali, K.M. Kandil and M.M. El-Maadawy, "Effects of some Parameters affecting the Crystallization Rate of Calcium Sulfate Dihydrate in Sodium Chloride Solution," J. Amer. Sci., 2011, 7, no. 6, 635.

2. M. Oner, O. Dogan and G. Oner, "The Influence of Polyelectrolytes Architecture on Calcium Sulfate Dihydrate Growth Retardation," J. Cryst. Growth, 1998, 186, 427.

3. F. Rahman, "Calcium Sulfate Precipitation Studies with Scale Inhibitors for Reverse Osmosis Desalination," Desalination, 2013, 319, 79.

4. Z. Amjad, "Applications of Antiscalants to Control Calcium Sulfate Scaling in Reverse

Osmosis Systems," Desalination, 1985, 54, 263. 
5. B.R. Smith and Y. Huilin, "Influence of Various Factors in the Performance Gypsum Scaling Retardants," Water Treatment, 1992, 7, 51.

6. Z. Amjad and J. Hooley, "Influence of Polyelectrolytes on the Crystal Growth of Calcium Sulfate Dihydrate," J. Colloid Interface Sci., 1986, 111, no. 2, 496.

7. K. Demadis and A. Stathoulopoulou, "Multifunctional, Environmentally Friendly Additives for Control of Inorganic Foulants in Industrial Water and Process Applications," Mater. Perform., 2006, 45, no. 1, 40.

8. D.L. Verraest, J.A. Peters, H. van Bekkum and G.M. van Rosmalen, "Carboxymethyl Inulin: A New Inhibitor for Calcium Carbonate Precipitation," J. Amer. Oil Chemists, 1996, 73, no. 1, 55.

9. E.H. Zeiher, "Introducing Hybrid Polymer Technology," Paper presented at the Association of Water Technologies Annual Convention, Atlanta, GA, 2011.

10. O. Dogan, E. Akyol and M. Oner, "Polyelectrolytes Inhibition Effect on the Crystallization of Gypsum," Crys. Res. Technol., 2004, 39, no. 12, 108.

11. Z. Amjad, "Gypsum Scale Inhibition Using Biopolymers and Synthetic Polymers," Mater. Perform., 2012, 51, no. 10, 48.

12. Z. Amjad, "Gypsum Scale Formation on Heat Exchanger Surfaces: The Influence of Natural and Synthetic Polyelectrolytes," Tenside Surf. Deterg., 2004, 41, no. 5, 214.

13. Z. Amjad, "Calcium Sulfate Dihydrate (Gypsum) Scale Formation on Heat Exchanger Surfaces: The Influence of Scale Inhibitors," J. Colloid Interface Sci., 1988, 123, no. 2, 523.

14. Z. Amjad and P.G. Koutsoukos, "Evaluation of Maleic Acid based Polymers as Scale Inhibitors and Dispersants for Industrial Water Applications," Desalination, 2014, 335, 55.

15. Z. Amjad, "Effect of Surfactants on Gypsum Scale Inhibition by Polymeric Inhibitors," Desalin. Water Treat.," 2011, 36, no. 1, 270.

16. T. Mullenberg and C. Cendir, "How Stripping Biofilm from the Cooling Water Loop Impacts Power Plant Production Output," Paper No. TP13-09, Cooling Technology Institute, 2009.

17. J.C. Cowan and D.J. Weintritt, Water-Formed Scale Deposits, Gulf Publising, Houston, TX, 1976.

18. D. Branson, D. Hasson and R. Semiat, "The Role of Gas Bubbling, Wall Crystallization and Particulate Deposition," Desalination, 1995, 100, 105.

19. W. Klima and G.H. Nancollas, "The Growth of Gypsum," Paper presented at the American Institute of Chemical Engineers Symposium Series on Crystallization and Precipitation Prevention, 1982.

20. Z. Amjad, R.T. Landgraf and J.L. Penn, "Calcium Sulfate Dihydrate (gypsum) Scale Formation by PAA, PAPEMP, and PAA/PAPEMP Blend," Int. J. Corros. Scale Inhib., 2014, 3, no. 1, 35. doi: 10.17675/2305-6894-2014-3-1-035-047 
21. K.D. Demadis, E. Neofotistou, E. Maavredaki, M. Tsiknakis, E. Saringiannidou and S.D. Katarachia, "Inorganic Foulants in Membrane Systems: Chemical Control Strategies and the Contribution of Green Chemistry," Desalination, 2005, 179, 281.

22. Z. Amjad and J. Penn, "Impact of Iron oxide (rust) on the Performance of Calcium Carbonate Inhibitors," Mater. Perform., 2014, 53, no. 11, 52.

23. Z. Amjad and D. Guyton, "Influence of Rust Particles on the Performance of Inhibitors," Ultrapure Water, 2011, 28, no. 6, 25.

24. R.W. Zuhl and Z. Amjad, "The Role of Polymers in Water Treatment Applications and Criteria for Comparing Alternatives," Paper presented at the Annual Convention of Association of Water Technologies, Las Vegas, NV, 1993.

25. Z. Amjad and R.W. Zuhl, "The Influence of Water Clarification Chemicals on Deposit Control Polymer Performance in Cooling Water Applications," Paper presented at the Annual Convention of Association of Water Technologies, Orlando, FL, 2002.

26. Z. Amjad, K.R. Workman and D.C. Castete, "Considerations in Membrane Cleaning," Ch. 7 in Reverse Osmosis: Membrane Technology, Water Chemistry, and Industrial Application, Ed. Z. Amjad, Van Nostrand Reinhold, New York, New York, 1993.

27. R.J. Cunningham, "What is Best Water Treatment Program for my Tower," Cooling Tower Inst. J., 2011, 32, 44.

28. Z. Amjad, "Performance of Calcium Phosphate Inhibitors in the Presence of Surfactants," Tenside Surf. Deterg., 2011, 48, 53.

29. Z. Amjad, "Effect of Surfactants on Gypsum Scale Inhibition by Polymeric inhibitors," Desalin. Water Treat., 2011, 36, 270.

30. Z. Amjad, "Effect of Surfactants on the Performance of Iron Oxide Dispersants," Tenside Surf. Deterg., 2011, 48, 190.

31. Z. Amjad, "Influence of Natural and Synthetic Additives on Calcium Carbonate Precipitation and Crystal Morphology," Tenside Surf. Deterg., 2006, 43, no. 4, 184.

32. E. Akyol, A. Bozkurt and M. Oner, "The Effects of Polyelectrolytes on the Inhibition and Aggregation of Calcium Oxalate Crystallization," Polym. Adv. Technol., 2006, 17, 58. 